\title{
Entrevista com Regina Przybycien: Debruçando-se sobre o mistério
}

Bronislawa Altman Mello

Polonês foi a língua da primeira infância da curitibana Regina Przybycien, nascida de pais poloneses. Dedicada, porém, ao aprendizado do português, ela o silenciou por anos a fio e só veio a estudá-lo com profundidade na maturidade, em um curso na Polônia. Foi então que Regina travou conhecimento com aquela que passaria a ser fonte de descobertas e companhia constante, a poeta polonesa Wislawa Szymborska. O encantamento foi tamanho que transbordou e ansiou ser compartilhado: quando Regina deu por si, já havia traduzido quarenta poemas da Nobel de Literatura, número que logo se ampliou para mais de cem, para nossa alegria. Generosa, culta, espirituosa, didática, Regina fala sobre seu começo na tradução e sobre as negociações indispensáveis entre as duas línguas que a constituem, para fazer com que os 'versos crocantes e estaladiços' da primeira ecoem na segunda, ainda que um tanto 'adocicados e melódicos'. Tudo isso e muito mais está na entrevista a seguir, dada entre os fins de março e o começo de abril deste ano de 2017.

Fale-nos um pouco da sua trajetória, especialmente sobre o que a levou para a literatura e para a tradução.

Sempre gostei de literatura. Quando adolescente devorava quaisquer livros que me caíssem nas mãos. (Na minha casa não havia livros - emprestava-os principalmente da Biblioteca Pública.) Lia romances cor-de-rosa de M. Delly, gibis que meu irmão colecionava, Júlio Verne, Monteiro Lobato, Érico Veríssimo e também clássicos da literatura mundial que havia na biblioteca do meu colégio, como Dostoievski, Turgueniev, Dumas e Dickens. Poesia eu lia menos, mas tinha 
um caderno no qual copiava alguns poemas favoritos. Lembro-me de Augusto dos Anjos, Alphonsus de Guimarães, Cecília Meireles, umas traduções de Edgar Allan Poe e Pablo Neruda. Poesia modernista brasileira só fui descobrir mais tarde.

A leitura de autores como Edgar Allan Poe, Ernest Hemingway, F. Scott Fitzgerald, Mark Twain, John Steinbeck e o fascínio pela música norte-americana me levaram a escolher o curso de Letras Português-Inglês na faculdade. Fiz o mestrado na Louisiana State University porque admirava os autores do sul dos Estados Unidos, sobretudo William Faulkner e Tennessee Williams. O doutorado, na UFMG, já foi direcionado para a poesia. Pesquisei a obra de Elizabeth Bishop. Dei aulas numa escola de inglês até fazer concurso para professora de literaturas de expressão inglesa na Universidade Federal de Ouro Preto. Após nove anos, fui transferida para a Universidade Federal do Paraná num momento em que esta instituição principiava a fazer acordos com universidades polonesas. Por ser descendente de poloneses me nomearam coordenadora do curso de extensão de polonês do Centro de Línguas e me envolveram nas negociações de acordos com a Polônia.

Eu não falava polonês, língua da minha primeira infância, havia mais de quarenta anos. $\mathrm{O}$ envolvimento com questões polonesas e certa vergonha de não falar a língua dos meus pais me fizeram decidir aprendê-la. Fiz um curso intensivo de polonês para estrangeiros na Universidade Jagielônica de Cracóvia em 1996, ano em que Wisława Szymborska ganhou o prêmio Nobel. As professoras do curso nos apresentaram alguns poemas que me fascinaram. Comecei a lê-los primeiro com a ajuda das traduções para o inglês. Mais tarde passei a traduzir alguns poemas favoritos como exercícios de leitura, para mim mesma. Essa atividade, que levou anos, resultou em uns quarenta e poucos poemas. Ao mostrar algumas dessas traduções para conhecidos, eles me aconselharam a publicá-las. Entrei em contato com a Cia. das Letras, que aceitou imediatamente publicar uma coletânea. Assim se deu minha estreia como tradutora, ofício que nunca pensara em exercer. Antes havia traduzido contos do inglês, mas nunca me ocorreu publicá-los. No Brasil há tradutores excelentes desse idioma, assim minha contribuição nunca me pareceu necessária. Já traduções do polonês eram raras, muitas delas de segunda mão, a partir do francês ou do inglês. O que me levou a publicar as traduções de Szymborska foi o desejo de tornar conhecida entre os apreciadores de poesia no Brasil uma grande poeta que aprendi a admirar incondicionalmente.

Há pouco comentei com amigos poloneses que Wislawa Saymborska é bem popular entre os amantes de poesia no Brasil. Ficaram muito surpresos. Porém é um fato comprovado, o qual 
se deve em grande parte ao seu trabalho e à divulgação de suas traduções pelas redes sociais. É gratificante para o tradutor ou é uma grande responsabilidade?

Szymborska já havia sido traduzida para dezenas de idiomas e eu sabia do enorme sucesso de seus livros na Itália, onde viraram best sellers, em parte graças às excelentes traduções de Pietro Marchesani. Tinha esperança de que minhas traduções fossem bem acolhidas, mas a grande repercussão do livro Poemas (2011) entre o público e os críticos brasileiros me surpreendeu. Nunca imaginei que meus poemas favoritos fossem cair no gosto de tantas pessoas. Vários poetas e críticos fizeram resenhas positivas em jornais e revistas. Leitores passaram a fazer comentários e reproduzir os poemas nas redes sociais e recebi mensagens pedindo que traduzisse mais. A editora me consultou sobre a possibilidade de traduzir mais poemas para uma segunda coletânea, que foi publicada em 2016 com o título Um amor feliz: O livro foi escolhido como melhor tradução de 2016 pela APCA (Associação Paulista de Críticos de Arte).

Ainda não me acostumei com toda essa repercussão e confesso que tenho sentimentos dúbios quanto às redes sociais. Por um lado, é gratificante constatar que Szymborska se tornou conhecida e apreciada no Brasil e saber que meu trabalho de tradução contribuiu para isso. Por outro, as redes sociais são como um território selvagem onde vale tudo. Nas vezes em que dei uma olhada nos poemas reproduzidos nesse meio me incomodaram a sem-cerimônia com que palavras às vezes são modificadas e a quantidade de erros de digitação cometidos.

Quais características da lingua polonesa ofereceram maiores dificuldades para a tradução para o português?

São línguas muito diferentes. Creio que as maiores dificuldades são os casos e o aspecto verbal. O polonês é uma língua declinável e possui sete casos. Substantivos, adjetivos, pronomes, numerais, todos declinam - um pesadelo para os falantes de línguas não declináveis! Quanto aos verbos, o sistema temporal em polonês é mais simples do que o português, com formas que indicam presente, passado e futuro. Extremamente complexa, porém, é a forma de marcar o aspecto verbal, que indica se uma ação iniciada terminou ou não. No português, indica-se o aspecto verbal com o uso de tempos específicos (por exemplo, um tempo passado perfeito e um tempo passado imperfeito). Além disso, a sua marcação depende, mais do que em polonês, do emprego de verbos auxiliares (como estar, começar, 
continuar, terminar) ou de locuções adverbiais que trazem uma nova informação semântica ao verbo a elas relacionado. No polonês, muitos verbos formam pares aspectuais: um verbo imperfectivo (para ação não concluída) e outro perfectivo (para ação concluída), formados geralmente por afixos, mas algumas vezes por verbos diferentes. Veja-se o tamanho do problema que se apresenta para a tradução no seguinte exemplo:

W najlepszym razie
będziesz, mój wierszu, uważnie csytany,
komentowany i zapamiętany.

W gorszym przypadku

tylko przeczytany. ${ }^{1}$

Na minha tradução:

Na melhor das hipóteses,

meu poema, você será lido atentamente,

comentado e lembrado.

Na pior das hipóteses

somente lido. ${ }^{2}$

$\mathrm{Na}$ primeira estrofe, os verbos çyytać (ler) e komentować (comentar) são verbos imperfectivos que indicam a ação de leitura e comentário sem marcar os limites temporais dessa ação. Já o verbo zapamietać (lembrar) é perfectivo e indica a conclusão da ação. O foco está no processo de ler e comentar, e não no seu resultado; pode-se interpretar que o poema será lido e comentado mais de uma vez e fixado na memória. Na segunda estrofe o verbo przecsytać, perfectivo, informa que a ação é realizada uma única vez e concluída. O foco está no resultado. O leitor leu até o fim, fechou o livro e acabou a relação dele com o poema. No português

1 SZYMBORSKA, W. Do własnego wiersza. Um amor feliæ: São Paulo, Cia. das Letras, 2016, p. 314.

2 SZYMBORSKA, W. Para o meu próprio poema. terão a página indicada no texto. , p. 315. As outras referências à obra da poeta 
não há como reproduzir esse contraste aspectual sem recorrer a locuções verbais ou adverbiais que encompridam demasiado o verso. E sem elas as ações ficam imprecisas na tradução.

Alguns tradutores, ao começar a tradução de um poema, faz̧em inicialmente uma metáfrase de todo ele, enquanto outros focam no elemento mais instigante. Como é sua estratégia como tradutora? Adota um esquema de etapas a ser seguido, on algo assim?

Faço várias leituras destacando o que não entendo e marcando detalhes como rimas, aliterações, imagens. Nessas leituras vou traduzindo mentalmente o poema, tentando sentir as palavras, o ritmo. No primeiro rascunho que escrevo já vou trabalhando a forma, deixando no original as palavras, expressões ou versos para os quais não encontro uma solução no momento. Coloco na margem diferentes opções de tradução para examinar depois. Nas revisões, vou burilando o poema diminuindo aos poucos as "pedras" - aquelas partes que resistem à tradução. Às vezes todo o poema flui, com exceção de uma única palavra ou expressão. Já aconteceu de levar muito tempo buscando uma solução satisfatória e não encontrá-la. Então, conforme o caso, descarto o poema ou me conformo com um resultado talvez não totalmente ruim, mas não tão bom.

Ser tradutor é saber conviver com a inevitável perda. Cotejando original e tradução, observei algumas alteracõoes no tempo verbal e nas categorias gramaticais, assim como algumas adições e inversões nas frases. Poderia discorrer um pouco sobre isso? Quais são as perdas mais importantes na tradução do polonês para o português? Seriam no âmbito fonético, da sonoridade, das assonâncias, da prosódia? Qual é sua reação a cada poema traduð̨ido?

Chamamos de perdas as alterações inevitáveis na passagem de uma língua para outra. Talvez devêssemos chamá-las de transformações porque perda significa empobrecimento. Existe uma conviç̧ão arraigada de que poesia é intraduzível e, no entanto, desde os primórdios da civilização ela é traduzida. Não teríamos acesso às grandes obras da humanidade se não houvesse traduções. Dito isso, as transformações pelas quais passa um poema ao ser vertido do polonês para o português são grandes devido às características próprias dessas línguas.

No nível sonoro, a língua polonesa possui uma quantidade enorme de encontros consonantais, fazendo com que no verso as aliterações sejam o recurso mais comum. Já no português a predominância de vogais torna quase inevitáveis 
as assonâncias. Lembro-me de um comentário de Elizabeth Bishop para Robert Lowell sobre a musicalidade natural das línguas latinas: "Oh, essas adocicadas línguas latinas com todas essas assonâncias...” Também na prosódia temos diferenças significativas. Ao contrário do português, no polonês a acentuação segue um padrão fixo. Todas as palavras são paroxítonas, (com exceção de algumas palavras proparoxítonas de origem estrangeira e na conjugação de verbos como, por exemplo, a primeira e segunda pessoa do plural do passado). Essa característica imprime uma cadência regular aos versos.

No nível morfológico e sintático também há grandes diferenças. Em polonês é possível formar adjetivos de uma imensa quantidade de substantivos e verbos. Em português essa capacidade é muito mais limitada, sendo frequentes as locuções adjetivas; por exemplo, dom drewniany só pode ser traduzido com uma locução: casa de madeira. Como nas outras línguas eslavas (menos o búlgaro e macedônio), a língua polonesa não tem artigo. Sendo uma língua declinável, é mais sintética e também permite uma série de inversões sintáticas sem prejuízo do significado. $\mathrm{Na}$ tradução, várias transformações são necessárias para não encompridar demasiado o verso e para que a dicção soe natural em português.

Wislawa Syymborska escreveu dois poemas com o nome 'Funeral', mas um deles parece representar o sepultamento de suas antigas ideias políticas: ela critica a idolatria aos líderes comunistas, quando antes havia escrito poemas panfletários enaltecendo esses mesmos líderes. $O$ poder oferece medalhas para 'acalentar' o povo. A frase 'entre eles e o povo' exprime a separação entre o poder e a população.

O fato de ter nascido no Brasil e de não ter vivido na Polônia dificultou a sua compreensão de poemas dedicados a certos fatos e momentos históricos da Polônia, como é o caso dos poemas 'Ainda', 'Funeral', 'Campo da Fome em Jaslo' e 'Inocência??

Até 1996, ano em que morei na Polônia pela primeira vez, meus conhecimentos da história da Polônia se limitavam aos episódios que se inserem no contexto mais amplo da história da Europa, como por exemplo a partilha da Polônia entre os impérios vizinhos no final do século XVIII, a Segunda Guerra Mundial, o holocausto, o Movimento Solidariedade e a história do Papa João Paulo II. Para um conhecimento mais amplo da história polonesa foi fundamental aprender a língua

3 Carta a Robert Lowell, 4 abr.1962, in Przybycien, R. Feijão preto e diamantes: O Brasil na obra de Elizabeth Bishop. Belo Horizonte: Editora UFMG, 2015, p. 161. 
para poder ler no original obras não traduzidas. Mais recentemente, os seis anos em que lecionei literatura brasileira na Universidade Jagielônica de Cracóvia me deram a oportunidade de conhecer melhor aspectos da história e da cultura do país.

As alusões nos poemas acima citados não foram difíceis de entender por tratarem (com exceção de "Funeral") de acontecimentos da Segunda Guerra Mundial. Mais difícil foi perceber, por exemplo, a relação bem menos evidente entre o tom sombrio de vários poemas dos anos 1980 e a decretação da lei marcial e do estado de exceção na Polônia que acabou com as esperanças trazidas pelo Movimento Solidariedade de se libertar da esfera soviética e instituir a democracia. Veja, por exemplo, os poemas "Filhos da época", "Torturas" e "Opinião sobre a pornografia" no livro Poemas.

É claro que, por eu ter nascido e vivido fora da Polônia toda a minha vida, muitas coisas me escapam, por isso foi fundamental, nas revisões da tradução, ter a ajuda de falantes nativos que conhecem bem sua língua, história e literatura. Sem eles meu trabalho teria ficado bem mais pobre.

Há várias ocorrências de domesticaşão muito bem fundamentadas no excelente prefácio ao volume Um Amor Feliz: por exemplo, no poema 'Elogio à Irmã', 'choc to brami jak. utwór Adama Macedonskiego' traduzido por 'embora isso soe repetitivo como uma litania'; ou no poema 'Mapa', a expressão idiomática 'cisza jak makiem zasial', traduzida por 'como poeira assentou o silêncio', ou ainda no poema 'Metafísica', o prato típico 'kluski ze skwarkami' traduzido como o tradicional prato brasileiro 'arroz com feijão'. Porém, no poema 'De uma expedição não realizada ao Himalaia', a expressão Jest czernone jabluszko præzekrojone na krayz' [maçãazinha vermelha cortada em crũ] sofreu uma alteração radical para 'tem rosa amarela tão formosa, tão bela'. Qual é o motivo?

As domesticações que tomei a liberdade de fazer são de tipos diversos. Primeiro, há elementos da cultura de partida que são obscuros para o leitor da tradução - como no poema "Elogio à irmã", a referência ao poeta Adam Macedoński, cuja poesia é bastante repetitiva. Optei por "litania" na tradução para dar a ideia de repetição, já que o nome do poeta não diz nada ao leitor brasileiro.

Uma solução mais radical ocorreu no poema "Recital da autora" (Poemas, p. 32), começando pelo título. "Wieczór autorski" significa tanto "noite do autor" como "noite da autora". Ao traduzi-lo como "Recital da autora", feminizei o eu lírico. (Não penso que seja um problema já que em vários outros poemas há marcas que indicam uma voz feminina.) Em um dos versos, no original polonês o eu 
lírico afirma que ser poeta é ver-se condenado à pena de ciężkie norwidy. Cyprian Norwid foi um poeta romântico que escreveu versos muito complexos e teve uma vida difícil, sem o reconhecimento de sua arte. Szymborska brinca com o nome de Norwid, transformando-o num substantivo comum. A tradução literal seria "estar condenado a norwids forçados" que faz um jogo com a expressão "estar condenado a duras penas" ou "a trabalhos forçados". Fiz um deslocamento radical ao transformar Norwid em Florbela Espanca. Em português o verso ficou: "estar condenado a duras florbelas". Eu poderia ter mantido a referência a Norwid sem prejuízo do verso, mas gostei de brincar com essa transposição cultural e acho que em "duras florbelas" a sonoridade ficou boa.

Outro tipo de transposição são as referências a elementos como a comida. No poema "Metafísica" a voz lírica encerra a reflexão filosófica com uma referência a um prato da cozinha polonesa: "kluski ze skwarkami. "Kluski" são um tipo de pasta mais grosseira, geralmente feita em casa, e "skwarki" são torresminhos. Não há em português uma palavra que traduza "kluski" exatamente, portanto, uma tradução mais próxima já exigiria uma adaptação. Como a ideia do poema é o contraste entre a metafísica e esse prato tão corriqueiro, optei por uma tradução cultural, substituindo-o pelo arroz com feijão. Fiz algo semelhante em "Alguns gostam de poesia" (Poemas, p.91). Neste poema o prato mencionado é "rosół z makaronem", um caldo de galinha ao qual se acrescenta um macarrão fininho cozido separadamente. É uma comida simples, do dia-a-dia. Como no exemplo acima, o que importa é o contraste, neste caso, da poesia com as coisas triviais. Assim, "rosół z makaronem" virou canja de galinha.

Szymborska também faz referências a provérbios, adágios, canções populares. No poema "De uma expedição não realizada ao Himalaia" o eu lírico menciona um verso de uma canção folclórica: "czerwone jabłuszko przekrojone na krzyż" ("maçãzinha vermelha cortada em cruz"). O leitor polonês reconhece a referência porque faz parte do seu repertório cultural, ao passo que para o leitor estrangeiro ela se perde. Por isso procurei uma canção brasileira que pudesse trazer para o leitor daqui uma ressonância semelhante. Encontrei no cancioneiro coletado por Villa Lobos a canção folclórica "Rosa amarela" que de quebra me deu uma boa rima: "tem rosa amarela, / tão formosa, tão bela" - uma licença poética da qual não me arrependo.

A última estrofe do poema 'Metafísica' me trouxe à lembrança um trecho do famoso poema de Fernando Pessoa, 'A Tabacaria': 'Come chocolates, pequena; Come chocolates! Olha que não há mais metafísica no mundo senão chocolates' e o poema 'Tem aqueles que' faz. lembrar o 'Poema 
em linha reta' pelo modo de olhar as atitudes de seus semelhantes. Diria que não se trata de influência, mas de confluência de ideias? Qual é a sua opinião?

São interessantes essas associações. Várias pessoas comentaram comigo que veem semelhanças entre alguns poemas de Szymborska e de Carlos Drummond de Andrade. Outras disseram que a coloquialidade da linguagem lembra a de Manuel Bandeira. É certo que existe confluência de ideias entre poetas de culturas diferentes porque a arte não está desvinculada de seu tempo e os modos de ver o mundo e as linguagens às vezes convergem. Por isso é possível ler reverberações de Pessoa em Szymborska. Mas também de Drummond e quiçá de outros poetas.

A primeira tradução polonesa de "Tabacaria" de Álvaro de Campos, heterônimo de Fernando Pessoa, foi publicada em 2002, portanto é possível que Szymborska a tenha lido, mas não acredito em influência. No poema pessoano, o eu lírico, dividido entre as aspirações metafísicas e o mundo real que se apresenta a seus olhos na figura da menina que come chocolates e no homem da tabacaria, tem uma visão desencantada e niilista de si e do mundo. Inveja a inocência da menina e o "Esteves sem metafísica" que sai da tabacaria, mas sabe que nunca será como eles.

No poema "Metafísica", Szymborska fala da transitoriedade de todas as coisas: tudo passa, "até isso de hoje você ter comido arroz com feijão". Essa intrusão do corriqueiro que quebra as especulações filosóficas, como vimos, também está presente em "Tabacaria", mas se atentarmos bem, Szymborska utiliza esse recurso em quase todos os poemas: ela os encerra com uma frase que esvazia o conteúdo elevado que vinha desenvolvendo causando um efeito irônico.

Como em muita poesia do século XX, nos poemas de Álvaro de Campos o eu lírico fala de si, tem uma consciência exacerbada da ferida narcísica, da sua separação do mundo. Ele é o homem moderno: inadequado, angustiado, melancólico. Já a poesia de Szymborska é menos centrada em si e mais no mundo. A voz lírica observa o micro e o macrocosmo, deslumbrando-se com seus mistérios. Mas é uma voz lúcida. Nela se misturam “o encantamento e o desespero”. (“Céu”, p. 188)

Na lingua polonesa, assim como em muitos outros idiomas, alguns tempos verbais identificam o gênero da pessoa em questão. No poema 'ABC', os verbos no passado identificam o gênero dos diversos personagens. Isso infelizmente se perde na tradução. Esse tipo de problema aparece com frequência? A propósito, no poema 'Uma ideia' aparece o pronome pessoal 'on' [ele], mas a sua opção foi utilizar o pronome feminino. Por quê? 
Este é um problema que diz respeito às características próprias das línguas. Nas línguas eslavas alguns tempos verbais têm uma forma masculina e outra feminina, deixando claro na enunciação o gênero do sujeito que fala. Essa característica se perde na tradução. Não seria possível reproduzi-la sem criar alguma esquisitice que os poemas de Szymborska não têm.

Quanto ao poema "Uma ideia", a palavra "pomysł" no original é masculina e consequentemente o eu lírico dialoga com "ele" ao longo do poema. A mudança de gênero no português é inevitável, já que a melhor tradução de "pomysł" é mesmo "ideia". Seria possível pensar em outras soluções, mas elas exigiriam malabarismos linguísticos que se distanciariam dos versos claros de Szymborska. Palavras têm gênero diferente nas línguas. A tradução de "la mer" do francês ou "la sangre" do espanhol, por exemplo, traz o mesmo tipo de problema já que no português são palavras masculinas.

A grafia da letra 'u' ou 'ó'é uma pedra no sapato de qualquerpolonês médio. A poeta resolven brincar com esse drama no 'Prólogo a uma comédia', dizendo: 'cultivava róze (rosas) com simples u (grafia errada)'. A sua solução 〈cultivava rosas com 'z') resolveu o dilema. Foi um insight imediato ou custou-lhe algum tempo? Aliás, como lidar com essa questão do tempo na tradução de poesia? Há traduções que ficam longamente engavetadas à espera de alguma solução que tarda a vir?

Neste caso da grafia de rosas com "z", a solução já havia sido utilizada na tradução inglesa de Barańczak e Cavanagh e na tradução italiana de Marchesani. Roubei-lhes a ideia porque dificilmente seria possível criar outra melhor. Já algumas expressões idiomáticas e provérbios ressignificados por Szymborska nos poemas me deram muita dor de cabeça e levei muito tempo para encontrar soluções nem sempre satisfatórias.

Dou um exemplo: em polonês existe o provérbio "szkoda czasu i atłasu". Uma tradução literal seria "não vale a pena gastar tempo e cetim". A enciclopédia PWN esclarece que a origem do provérbio se deve a uma declaração do rei da Polônia Estanislau Augusto. Ao receber, na sua coroação, o panegírico de um mau poeta escrito num pano de cetim branco, o rei teria proferido essas palavras. Não seria difícil encontrar provérbios portugueses equivalentes (uma tradução possível seria "perder o tempo e o latim"), mas nada é tão simples quando se trata de Szymborska. No poema sem título que começa com o verso "Estou perto demais para ele sonhar comigo", a voz lírica (feminina, como indicam os adjetivos e os verbos) lamenta a indiferença do amado que dorme a seu lado. 
Bienda,

ograniczona do własnej postaci,

a byłam brzoza, a byłam jaszczurka,

a wychodzitam z.crasón $i$ attasón

mieniąc się kolorami skór. (p. 98)

Na minha tradução:

Pobre de mim,

limitada à minha própria forma,

eu que fui bétula, que fui lagartixa,

e largava os anos e panos

cambiando as cores das peles. (p. 99)

Como em vários poemas szymborskianos, o tema da evolução das espécies aparece ligado a um filosofar sobre a condição humana. O eu lírico compara sua forma atual às transformações pelas quais passou na evolução. $O$ provérbio no poema sofreu uma transformação sintática e semântica: está no genitivo plural, significando literalmente "saía dos tempos e dos cetins". Minha solução foi tentar me aproximar desse sentido literal buscando ao mesmo tempo manter a rima. Não fiquei muito satisfeita com o resultado, mas foi o melhor que consegui depois de várias tentativas.

O que deve ser evitado numa tradução poética?

Não existe receita para uma boa tradução poética. Há boas traduções estrangeirizadoras, que procuram aproximar o poema da língua e da cultura de partida. Esse tipo de abordagem visa abrir novos horizontes para o leitor, mostrar-lhe coisas que desconhece. Em algumas dessas traduções utiliza-se o recurso de notas de rodapé para explicar pontos obscuros. Por outro lado, há traduções domesticadoras extremamente criativas, geniais até, como algumas recriações dos irmãos Campos.

Só posso falar das minhas opções de tradução. Não utilizo notas de rodapé nem longos posfácios para esclarecer ou justificar cada item que apresenta dificuldades. Esse tipo de recurso é ótimo para professores e estudantes de literatura e especialistas em tradução, mas não serve para o público leitor que aprecia poesia 
e só quer sentir um prazer lúdico na leitura. Por outro lado, também não recrio o poema de tal forma que adquira uma existência própria, primeiro porque não sou poeta e não saberia fazê-lo e segundo porque julgo importante manter uma relação com o sentido do original. Procuro observar o tom e recriar, na medida do possível, o esquema de rimas e a extensão dos versos. Acho que minhas soluções ficam no meio do caminho.

Com delicadeza, sensibilidade e humor, Wislawa Saymborska vai penetrando no cotidiano, vasculhando as profundezas da alma humana, ora maravilhada com o mistério do universo, ora angustiada pela finitude e brevidade da nossa existência. Palavras dela, ao terminar o poema 'Céu': 'meus sinais particulares são o encantamento e o desespero'. A linguagem dela nunca é banal on estereotipada e é a sua eloquência sutil que atrai o leitor. Chama a atenção o que alguns poetas e tradutores dizem dos poemas dela:

"São enganosamente simples". "A tradução deles foi como lapidação de diamantes"- Piotr Kaminski (tradutor para o francês)

"Ela mudou a minha visão do mundo, das coisas, até mesmo de um simples botão: possuía um dom que se revelava a mesmo tempo pela grandeza e pela modéstia" - Claire Cavanangh (tradutora para o inglês)

"Sua poesia é compreensivel em todos os idiomas. É uma poesia feita para ser traduzida, pois penetra nas situações humanas cheia de bumor e ao mesmo tempo, de reflexão filosófica" - Piotr Wojciechowski

"Quando você captar a entonação dela, a calorosa ironia, ai então conseguirá reprodużir a melodia de seus versos" - Rafi Weichert (tradutor para o hebraico)

Concorda com essas afirmações ou faria algum reparo nelas? O que Regina Praybycien gostaria de acrescentar depois de ter traduz̨ido deženas de poemas de Wislawa Szymborska para o português?

Concordo com todas as afirmações porque há uma Szymborska para cada leitor. A sua poesia alcança um grande número de leitores em todo o mundo porque fala dos grandes temas que nos encantam ou assombram e o faz de maneira inusitada, surpreendente. A poeta se debruça sobre o mistério presente numa pedra, num grão de areia, num micróbio ou na vastidão do cosmo, reflete sobre a história humana e a história do planeta ou tece comentários sobre o cotidiano, sempre com lucidez e modéstia, numa linguagem clara, concisa, sem hermetismo. Seu humor sem acidez consegue mitigar mesmo os temas mais horríveis. Para além dessas considerações, sua poesia tem um significado muito pessoal para mim. Foi nela que reconheci as sonoridades da língua perdida na minha infância, língua 
materna, que cedo foi substituída pelo português. Traduzi-la foi um processo visceral que envolveu bem mais que o intelecto: foi uma negociação entre as duas línguas que me constituíram. 